\title{
Research on the Parking Resource Sharing Model in Urban Residential Area
}

\section{Bo Gao}

Liaoning Police College, Dalian City, Liaoning Province, 116036, China

\author{
Keywords: Parking Sharing Model; Residential Area; Resource Sharing
}

\begin{abstract}
In view of the parking problem in old city, the concept of parking sharing model is defined. The conditions and constraints of 4 types of sharing models are analyzed, respectively are the internal exploitation of residential areas, the sharing of surrounding roads, the sharing among different constructions and the sharing of surrounding lands. Combing with the above 4 types of conditions and constraints, the time of implementation of sharing models and the post security of parking sharing models were proposed. At last, typical statistics were selected for analysis.
\end{abstract}

\section{Introduction}

Due to the continuous growth of vehicle ownership and the limited parking resources, the parking problem is becoming more and more serious. The simple increase of the number of parking supplies does not significantly alleviate the parking contradiction but stimulate the parking demand seriously. Therefore, how to revitalize the limited parking facilities in cities, improve the utilization efficiency of parking facilities and enhance the supply capacity of existing parking facilities has become an urgent problem. The parking sharing model, as an intensive resource management model, is one of the approaches to solve the parking contradiction under the current situation of China.

\section{Interpretation of Parking Sharing Model}

\subsection{The concept of parking sharing model}

The concept of parking sharing is divided into two levels. The first level is to share the parking resources macroscopically, which includes four aspects: the internal exploitation of residential areas, the sharing of surrounding roads, the sharing of constructions and the sharing of surrounding land resources. The parking sharing in this level means the sharing of space resources with different functions. The second level is relatively microscopic, which utilizes the interlacing of time to use the adjacent parking facilities, so as to realize the parking resources sharing. To sum up, the parking resources sharing embodies the idea of a coordination and optimization of regional resources.

\subsection{The realization of parking sharing model}

The parking sharing in the same construction: reconstructing non parking space (such as green space) and negotiating with space owners to use non parking space as a parking space. The parking sharing among different constructions: different types of constructions make use of their different characteristics of parking time, accompanying with agreements, to achieve the effective use of parking resources and a win-win goal. The parking sharing of surrounding roads: Through adopting the surrounding roads and the approvals of relevant departments, the road parking areas are established to realize the parking sharing of road resources, which can not affect surrounding traffic conditions. The parking sharing of surrounding land resources: Through adopting the surrounding land resources and the approvals of relevant departments, the public parking areas are established to realize the sharing of surrounding land resources on the basis of parking demands and the opportunity cost of land resources.

\section{The Constraints and Conditions of Parking Sharing in Residential Areas}

The sharing of parking resources involves different attributes of space and different interests of 
populations, which make the sharing of parking resources face different conditions and constraints. This paper analyzed the conditions and constraints of various types of parking sharing, weighted the implementation cost of different types of parking sharing and proposed various types of implementation time.

\subsection{The exploitation of interior spaces of constructions}

Conditions: enough spaces for developments (ground and underground), adequate construction funds, the approvals of owners and the approvals of property managements.

Constraints: the contradiction between residents and owners, the interference of parking individuals to non parking individuals, insufficient construction funds.

Timing of implementation: the parking problems should be considered in the initial stage of parking contradictions.

Analysis: the exploitation of interior spaces of constructions involves the interest conflicts between two different groups: the parking people and non parking people. The key problem should be considered is to solve the interest conflicts among them.

\subsection{The parking sharing among different constructions}

Conditions: property managements, approvals of owners, the basis of parking sharing between different residential areas.

Contradiction: recognition of parking sharing, establishment of information platform, coordination of parking costs, safety between different residential areas and wishes of owners of parking areas.

Timing of implementation: the interior space of residential areas is unable to digest the overflowing parking demands, a comprehensive evaluation of cost of sharing is conducted, and then targeted methods are implemented.

Analysis:

(1) the characteristics of parking demands in different types of buildings. The premise of the opening of parking facilities is to satisfy the parking needs of the building. Under the condition that the parking facilities are obviously idle, it could share the parking spaces to others. In general, the idle features of parking facilities is closely related to the types of building developments.

(2) the will of parking space owners. The basic types of the use of parking facilities include fixed use, fixed renting and temporary renting. Fixed use: a parking space is exclusively used by its owner. Fixed renting: a parking space is used for rental by lessee, and can be divided into fixed parking renting and mobile parking renting. Temporary renting: a parking space is used for rental by individuals temporarily.

Since there is no specific users, the temporary renting has high flexibility. On the contrary, the fixed use and fixed renting have specific users so that the willingness of them determines whether the parking space could be shared. This paper made a survey of exclusive users of parking spaces in Beijing, and the results could be seen as Table 1.

Table 1 The willingness about parking space sharing of their owners

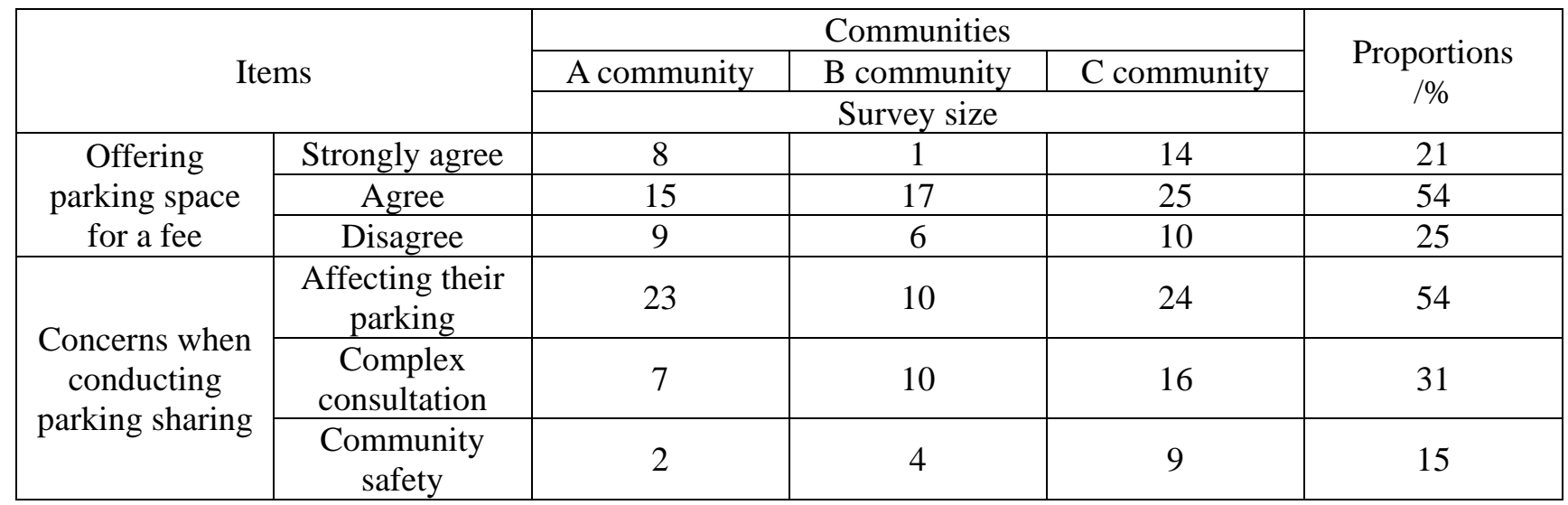


The results show that $21 \%$ of parking space owners strongly agree to offering parking space for a fee, and then 54\% of them consider they would conduct the paid services under proper managements. Eventually, most of the owners mention two problems, respectively are complex consultation with other owners and affecting their own parking.

\subsection{The parking sharing in surrounding loads}

Conditions: available space in surrounding roads, approvals of relative departments.

Constraints: enhanced pressure on road networks, the safety and convenience of parking.

Timing of implementation: the interior space of residential areas is unable to digest the overflowing parking demands, a comprehensive evaluation of cost of sharing is conducted, and then targeted methods are implemented.

Analysis: when planning the roadside parking facilities, parking planners should consider many factors, such as traffic flows, intersection features, the number of lanes, the road width and so on. The influence of road width on roadside parking is listed in Table 2.

Table 2 The influence of road width on roadside parking

\begin{tabular}{|c|c|c|c|}
\hline \multicolumn{2}{|c|}{ Categories } & Road width /m & Parking condition \\
\hline Roads & \multirow{3}{*}{ One-way roads } & $>12 \mathrm{~m}$ & Parking on both sides \\
\hline & & $8 \sim 12 \mathrm{~m}$ & Parking on one side \\
\hline & & $<8 \mathrm{~m}$ & No parking \\
\hline & \multirow{3}{*}{ Two-way roads } & $>9 m$ & Parking on both sides \\
\hline & & $6 \sim 9 \mathrm{~m}$ & Parking on one side \\
\hline & & $<6 \mathrm{~m}$ & No parking \\
\hline \multirow{3}{*}{\multicolumn{2}{|c|}{ Lane }} & $>9 \mathrm{~m}$ & Parking on both sides \\
\hline & & $6 \sim 9 \mathrm{~m}$ & Parking on one side \\
\hline & & $<6 \mathrm{~m}$ & No parking \\
\hline
\end{tabular}

\subsection{The parking sharing in surrounding lands}

Conditions: sufficient lands, construction funds and approvals of relative departments.

Constraints: parking fees can not be accepted by residents, parking facilities are far from the residential areas, conflicts with urban comprehensive planning and high cost of lands.

Timing of implementation: when the above three sharing models can not be implemented, this sharing model would be considered.

Analysis: the sharing of surrounding lands is to utilize land resources around the residential areas to establish public parking areas. The establishment of public parking areas is based on the urban comprehensive planning and the behavior of owners. In addition, when making decisions, planners should consider several factors, such as the vehicle accessibility, the service radius, the construction costs, the coordination of urban comprehensive planning, the effective utilization of public space and the protection of urban culture, etc.

\section{Post Security Measures}

\subsection{Motivation mechanism}

(1) the government motivation: the mode of parking sharing is confront with the coordination of different departments. If governments could introduce some relevant policies, which play guiding roles in decision-making, the behavior of parking facility managements would have standards to abide. (2) the establishment of parking information platform: relevant database in parking system is established. Furthermore, a regional real-time parking information sharing platform, the LED display technology and the GPS technology are adopted to release parking information to public, which is convenient for vehicle owners to select parking space reasonably. 


\subsection{Management}

(1) establishing the standard of parking fee: a reasonable parking fee standard not only reflect the construction and operation costs of parking facilities, but also be beneficial to balance the supply and demand of parking facilities. To a large extent, the parking fee standard can be regulated by the markets. When parking supply and demand is not balanced and the parking demand can not be satisfied, it is necessary for governments to participate in the parking pricing. (2) The recognition mechanism of parking sharing: vehicle owners might be faced with how to identify whether the vehicle has the right to adopt the parking sharing. The establishment of parking sharing identification mechanism can standard the behaviors of parking sharing, and the information management platform can be adopted to recognize parking vehicles.

\section{Summary}

This paper mainly analyzed 4 types of parking sharing models, which include the internal exploitation of residential areas, the sharing of surrounding roads, the sharing among different constructions and the sharing of surrounding lands. Furthermore, some typical problem were considered during the research, such as conditions, constraints, timing of implementation and analysis. Besides, post security measures were proposed to guarantee the normal implementation of different parking sharing models. At last, in according to relevant researches, several surveys were adopted to verify the argument, and then the mission in future is to apply the above parking sharing models to practice so that enhance the parking capacity of urban residential areas.

\section{References}

[1] Abeles Phillips Preiss, Shapiro. Detailed Technical Analysis on Shared Parking [R]. Portland: Portland Metro, 2002.

[2] Dowling Associates, Inc. MacArthur BART Transit Village Shared Parking [R]. 2007, 3(5): 1-2

[3] Litman Todd. Parking Management: Strategies, Evaluation and Planning [R]. Victoria: Victoria Transport Policy Institute, 2006.

[4] Guo Xueqin. Research on the Planning of Urban Public Parking Lot [D]. Beijing: Beijing Jiaotong University, 2006.

[5] Chen Yongmao, Guo Xiucheng, Ram Jiangyu. The Shared Parking Feasibility of Appertaining Parking Facilities to the Building in Cities [J]. Modern Urban Research, 2010, 6(1): 23-27.

[6] Xiao Fei, Zhang Lixue, Yan Kefei. Parking Demand Forecasting Based on Parking Space Sharing [J]. Urban Transport of China, 2009, 7(3): 73-79.

[7] Ran Jiangyu, Guo Xiucheng, Chen Yongmao. A Framework for CBD Parking Demand Forecasting [J]. Urban Transport of China, 2009, 7(6): 59-65. 